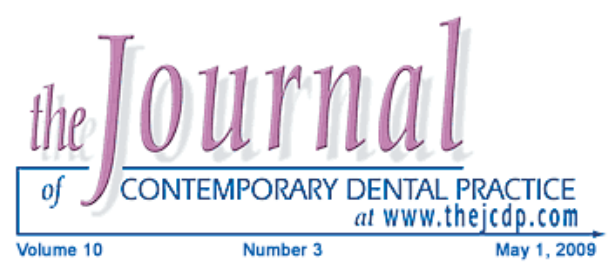

\title{
The Effect of Different Adhesive Types and Curing Methods on Microleakage and the Marginal Adaptation of Composite Veneers
}

\author{
Fathemeh Maleknejad, DDS, MS; Horieh Moosavi, DDS, MS; \\ Resa Shahriari, DDS; Nasrin Sarabi, DDS, MS;
}

Taybeh Shayankhah, DDS
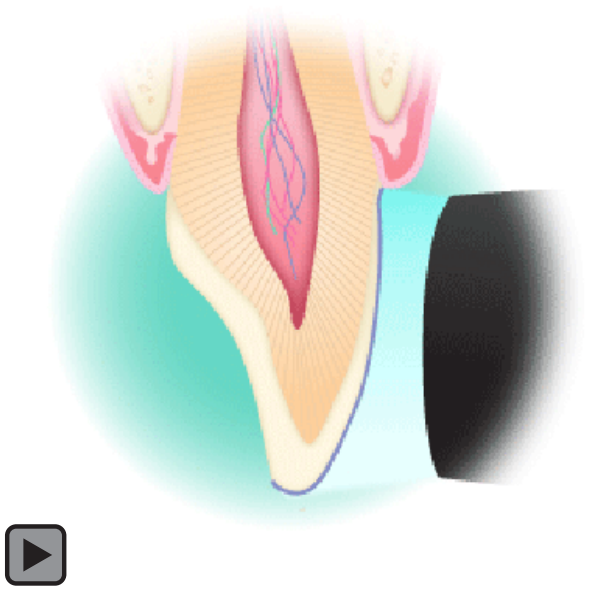

Abstract

Aim: The aim of this in vitro study was to evaluate the influence of application techniques (with pre-curing vs without pre-curing) for dentin adhesive on microleakage and marginal adaptation of indirect composite veneer restorations.

Methods and Materials: A total-etch bonding system, Excite/Variolink II (EXV), and a self-etching primer system, Panavia F2.0 (PF2), were used in the study. Forty-eight human central incisors were prepared for composite veneer restorations. The teeth were divided into two groups $(n=24)$. For each resin cement, one half of each experimental group included an adhesive pre-cure (PC) with a halogen light source while the other half received no pre-cure (NPC) prior to resin cement insertion. Thus, four experimental groups were created: $A$ (PC+EXV), B (NPC+EXV), C (PC+PF2), and D (NPC+PF2). Veneers made of Tetric Ceram resin composite were cemented using dual-cured resin luting agents. After storage in distilled water at $37^{\circ} \mathrm{C}$ for 24 hours, the teeth were prepared for marginal leakage. Two samples of each group were selected at random for scanning electron microscopic (SEM) observation and evaluation of marginal adaptation at 1050x magnification. Data were analyzed using the Kruskal-Wallis and Mann-Whitney tests $(\bigoplus<0.05)$.

Results: The highest and lowest microleakage values were observed in dentinal margins of groups $B$ and $A$, respectively. Dentin margins opposite to enamel margins had a significant difference in microleakage values of

(C) Seer Publishing 
PC and NPC groups $(P<0.05)$. The influence of the adhesive pre-cure was more pronounced than the type of resin cement used. No adhesive layer was visualized for the adhesives used without employing the pre-curing step.

Conclusion: The effect of pre-cured adhesives was not material specific. The pre-cured adhesives showed the best resistance to dye penetration although the film thickness of these luting agents was only slightly increased.

Clinical Significance: Different curing methods (with pre-curing/without pre-curing) regardless of total-etch or self-etch adhesive systems influenced microleakage and the marginal adaptation, especially dentin margins of indirect composite veneers.

Keywords: Composite veneer, adhesive systems, microleakage, SEM, marginal adaptation, curing method

Citation: Maleknejad F, Moosavi H, Shahriari R, Sarabi S, Shayankhah T. The Effect of Different Adhesive Types and Curing Methods on Microleakage and the Marginal Adaptation of Composite Veneers. J Contemp Dent Pract 2009 May; (10)3:018-026.

\section{Introduction}

Development of adhesive materials that facilitates placement of conservative restorations and the achievement of excellent esthetic outcome along with adequate strength accounts for the increased use of bonded restorations in dentistry. The composite veneers bonded to enamel after minimal tooth preparation is among this type of restoration to gain popularity. ${ }^{2,3}$

Ceromer resin shows promise as a cost effective restorative material for the fabrication of esthetic anterior laminates as an alternative to porcelain laminates for restoration of discolored and malformed anterior teeth. ${ }^{4}$ The longevity of indirect restorations fabricated with indirect composite resins is dependent on favorable clinical and cementation techniques.

The cementation technique used is determined by the type and composition of restorative material as well as the selected cement. ${ }^{5}$ Despite the increased efficiency achieved with dental adhesives during the last decade, the seal and marginal adaptation of bonded composite veneers remains a critical problem, especially when the cervical margin is placed on dentin. ${ }^{6}$

In these cases the cementation procedure becomes even more critical, and the strength and durability of bond between composite, luting cement, and enamel/dentin interference play an important role in the long-term success

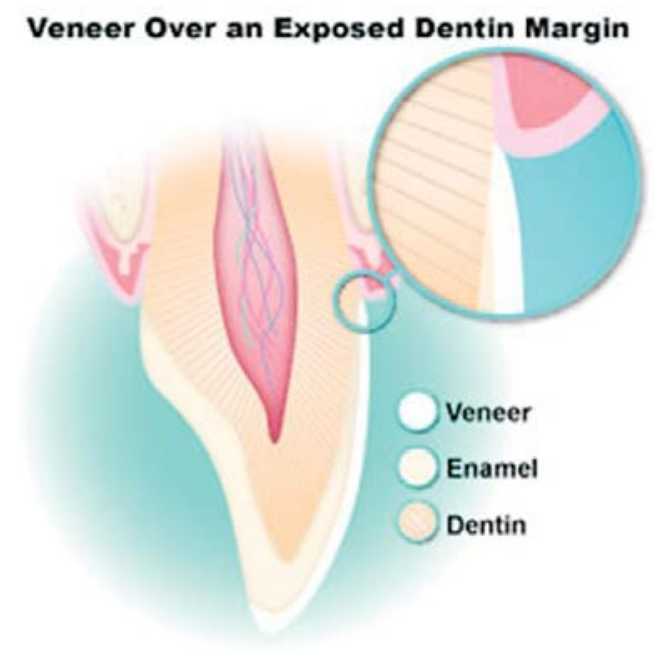

of composite veneers. High failure rates with veneers have been associated with large exposed dentin cervical margins which have been regarded as a problematic area of tooth preparations to achieve a perfect marginal seal. ${ }^{3}$ Exposure of dentin is common, particularly in the gingival third of a veneer preparation due to the thin enamel layer located in this region of a prepared tooth.

Both total-etch and self-etch bonding systems are designed for adhesion of indirect veneers to tooth structure. In both of these systems manufacturers recommend applying the adhesive on the tooth surface without light curing before cementation. However, the lack of pre-curing may cause the 
adhesive layer to become too thin and insufficient for adequate bonding.

The clinical success of cemented restorations has been evaluated by measuring marginal fit and microleakage for many years. However, there is no restoration or luting material able to achieve a complete marginal seal. ${ }^{8,9}$ In bonded composite restorations microleakage is associated with the loss of margin integrity and bonding to the tooth structure, which leads to other problems such as secondary caries, post-operative sensitivity, pulpal inflammation, staining, and plaque accumulation. ${ }^{9,10,11}$ This is due to the passage of bacteria, fluids, molecules, and ions between tooth structure and the cemented restoration. ${ }^{12}$

The aim of this study was to test the null hypothesis that the application of various resin cements with different curing methods (with precuring vs without pre-curing) leads to similar marginal adaptation and microleakage in dentin and enamel margins.

\section{Methods and Materials}

\section{Specimen Preparation}

Forty-eight sound human maxillary incisors, recently extracted for periodontal reasons, were selected for the study. Residual soft tissues were removed by scaling and storing the teeth in distilled water containing thymol crystals during the interval between extraction and use in this in vitro study. One clinician prepared all teeth for facial indirect composite veneers using chamferended, parallel-sided diamond burs (Brasseler USA, Savannah, GA, USA) in a high speed handpiece with air water spray. The bur was replaced after every four preparations.

The veneer cavities were prepared using the window method. The margins ended as a butt joint at the incisal edge and as a chamfer extending $1 \mathrm{~mm}$ apically from the cementoenamel junction along the cervical margin. The preparation was extended about halfway into the interproximal surfaces of the teeth. The cavities were finished using a matching diamond finishing bur (40 $\mu \mathrm{m}$ particle size, Brasseler, Savannah, GA, USA).
Thereafter, all veneers were fabricated by placing Tetric Ceram A2 ${ }^{\mathrm{TM}}$ resin composite (IvoclarVivadent, Schaan, Liechtenstein) directly into each preparation using water as a separating medium. Each increment was photocured for 20 seconds using a visible light-curing unit (Optilux 500, Demetron-Kerr, Orange, CA, USA) at $500 \mathrm{~mW} / \mathrm{cm}^{2}$. Then veneers removed on the prepared tooth and additional polymerization was performed for 7 minutes at $125^{\circ} \mathrm{C}$ in a Coltene ${ }^{\circledR}$ D.I.-500 oven specified for resin composite (Coltène AG, Alstätten, Switzerland). The internal surfaces of the veneers were then sandblasted with $50 \mu \mathrm{m} \mathrm{Al}_{2} \mathrm{O}_{3}$ powder at bars of pressure. Then the teeth were divided randomly into four groups according to type of cement and curing method to be used for cementation of the veneers as follows:

- Group A: The veneers were cemented on the teeth using Excite ${ }^{\circledast}$ (Ivoclar-Vivadent AG, Schaan, Liechtenstein) adhesive with pre-curing and Variolink ${ }^{\circledR}$ II (Ivoclar-Vivadent AG, Schaan, Liechtenstein) resin cement (PC+EXV).

- Group B: The veneers were cemented on the teeth using Excite ${ }^{\circledast}$ adhesive without pre-curing and Variolink ${ }^{\circledast}$ II resin cement (NPC+EXV).

- Group C: The veneers were cemented on the teeth using ED Primer II (Kuraray Medical, Okayama, Japan) adhesive with precuring and Panavia F2.0 (Kuraray Medical, Okayama, Japan) resin cement (PC+PF2).

- Group D: The veneers were cemented on the teeth using ED Primer II adhesive without pre-curing and Panavia F2.0 resin cement (NPC+PF2).

The teeth treatment strategies and materials used for each group are summarized in Table 1.

The systematic technique employing veneer and tooth preparations for veneer placement with Excite/Variolink (EXV) is shown in Table 2.

The systematic technique employing veneer and tooth preparations for veneer placement with ED Primer II/ Panavia F2.0 (PF2) is shown in Table 3. 
Table 1. Dentin treatments and materials used for each experimental group.

\begin{tabular}{|c|c|c|c|c|c|}
\hline Group & Substance & $n$ & Etching & Priming & Bonding \\
\hline Group $A(P C+E X V)$ & $\begin{array}{l}\text { Excite } \\
\text { PC }\end{array}$ & 12 & $\begin{array}{l}\text { - Etch with } 35 \% \\
\text { phosphoric acid } 15 \\
\text { seconds } \\
\text { - Rinse } 20 \text { seconds }\end{array}$ & $\mathrm{N} / \mathrm{A}$ & $\begin{array}{l}\text { - Apply with brush } \\
\text { for } 10 \text { seconds } \\
\text { - Air thin for } 3 \\
\text { seconds } \\
\text { - Light cure for } 20 \\
\text { seconds }\end{array}$ \\
\hline $\begin{array}{l}\text { Group B } \\
\text { (NPC+EXV) }\end{array}$ & $\begin{array}{l}\text { Excite } \\
\text { NPC }\end{array}$ & 12 & $\begin{array}{l}\text { - Etch with } 35 \% \\
\text { phosphoric acid } 15 \\
\text { seconds } \\
\text { - Rinse } 20 \text { seconds }\end{array}$ & N/A & $\begin{array}{l}\text { - Apply with brush } \\
\text { for } 10 \text { seconds } \\
\text { - Air thin for } 3 \\
\text { seconds } \\
\text { - Do not light cure }\end{array}$ \\
\hline $\begin{array}{l}\text { Group C } \\
\text { (PC+PF 2.0) }\end{array}$ & $\begin{array}{l}\text { Panavia F2.0 } \\
\text { PC }\end{array}$ & 12 & N/A & \multicolumn{2}{|c|}{$\begin{array}{l}\text { - Apply with brush for } 10 \text { seconds } \\
\text { - Wait for } 30 \text { seconds } \\
\text { - Dry with air spray for } 3 \text { seconds } \\
\text { - Light cure for } 20 \text { seconds }\end{array}$} \\
\hline $\begin{array}{l}\text { Group D (NPC+PF } \\
2.0)\end{array}$ & $\begin{array}{l}\text { Panavia F2.0 } \\
\text { NPC }\end{array}$ & 12 & N/A & \multicolumn{2}{|c|}{$\begin{array}{l}\text { - Apply with brush for } 10 \text { seconds } \\
\text { - Wait for } 30 \text { seconds } \\
\text { - Dry with air spray for } 3 \text { seconds } \\
\text { - Do not light cure }\end{array}$} \\
\hline
\end{tabular}

Table 2. Technique used for Excite/Variolink (EXV).

\begin{tabular}{|l|l|}
\hline \multicolumn{2}{|c|}{ Excite Nariolink II (EXV) } \\
\hline Veneer Preparation & $\begin{array}{l}\text { - Sandblast with } 50 \mu \text { alumina powder at } 2 \text { Bar pressure for } 7 \text { seconds } \\
\text { - Etch with } 35 \% \text { phosphoric acid for } 60 \text { seconds } \\
\text { - Rinse for } 30 \text { seconds and dry } \\
\text { - Apply the silane to the internal surface of veneer with brush for } 60 \text { seconds } \\
\text { - Wait for } 30 \text { seconds and then dry the silane with air spray } \\
\text { - Apply the adhesive to the internal surface of veneer } \\
\text { - Air thin the adhesive }\end{array}$ \\
\hline Tooth Preparation & $\begin{array}{l}\text { - Clean the prepared surface with pumice and water } \\
\text { - Etch the enamel surface for } 15-30 \text { seconds and the dentinal surface for } 10-15 \\
\text { seconds }\end{array}$ \\
- Remove excess water but DO NOT over dry dentinal surfaces \\
- Apply adhesive \\
- Dry the adhesive with air spray for $1-3$ seconds \\
- Light cure the adhesive for 20 seconds just in PC group
\end{tabular}


Table 3. Technique used for ED Primer II/Panavia F2.0 (PF2).

\begin{tabular}{|l|l|}
\hline \multicolumn{2}{|c|}{ ED Primer III Panavia F2.0 (PF2) } \\
\hline Veneer Preparation & $\begin{array}{l}\text { - Sandblast the internal surface of the veneer with } 50 \mu \text { alumina powder at } 2 \text { Bar } \\
\text { pressure for } 7 \text { seconds } \\
\text { - Etch with k-etchant gel for } 60 \text { seconds } \\
\text { - Rinse for } 30 \text { seconds and dry } \\
\text { - Mix Clearfil SE Bond primer and Clearfil porcelain bond activator in 1:1 ratio and } \\
\text { apply the mixture to the internal surface of veneer with brush } \\
\text { - Wait for } 30 \text { seconds to dry }\end{array}$ \\
\hline Tooth Preparation & $\begin{array}{l}\text { - Clean the prepared surface with pumice and water } \\
\text { - Mix ED Primer II A \& B in 1:1 ratio and apply the mixture to the internal surface of } \\
\text { veneer } \\
\text { - Wait for } 30 \text { seconds and then dry with air spray for } 30 \text { seconds } \\
\text { - Light cure for } 20 \text { seconds just in PC group }\end{array}$ \\
\hline Veneer Seating & $\begin{array}{l}\text { - Apply base cement to veneer } \\
\text { - Seat the veneer on the tooth with mild pressure and maintain pressure for } 10-20 \\
\text { seconds } \\
\text { - Remove excess cement from the borders } \\
\text { - Light cure for } 40 \text { seconds from each side }\end{array}$ \\
\hline
\end{tabular}

\section{Microleakage Test}

Following cementation, finishing and polishing procedures were done; the veneered teeth were stored in distilled water at body temperature for 24 hours. Next, they were thermocycled in water at $5-55^{\circ} \mathrm{C}$ for 1000 cycles with a 20 second dwell time at each temperature and a 10 second transfer time for a total of 60 seconds per cycle. The roots and tooth surfaces were then covered with two layers of quick drying fingernail varnish that extended to within $1 \mathrm{~mm}$ of the margins of the composite veneer restorations to prevent dye penetration from these parts of the teeth. The teeth were then stored in $0.5 \%$ basic fuchsine solution (Fluka, Buchs, Switzerland) for 24 hours at $37^{\circ} \mathrm{C}$.

After rinsing the teeth under pressured water, the specimens were mounted in polyester resin and sectioned in a bucco-lingual direction perpendicular to the long axis of the teeth with the aid of a slowly rotating diamond disc (Isomet Low Speed Saw 11-1180, AB Bühler Ltd, Chicago, IL, USA) under a water coolant to obtain three slices from each tooth. The sectioned surfaces were polished using sandpaper descending in abrasivity to a fine 2000 grit and analyzed for microleakage at the cervical (dentinal) and incisal (enamel) margins using a steromicroscope (Blue light industry, Waltham, MA, USA) at 40x magnification. Microleakage values were obtained by measuring stain penetration for the total surface length. Measurements were done separately for the dentin and the enamel and were expressed as a percentage of the total length of the veneer preparation.

The nonparametric Mann-Whitney $U$ and KruskalWallis tests were used for statistical analysis. The statistical difference was considered significant if $\mathrm{P}<0.05$ and performed using SPSS version 11.5 software (SPSS Inc., Chicago, IL, USA). 
Randomly two sectioned specimens from each group were prepared for scanning electron microscope (SEM) analysis. Each section was sequentially polished with 600 up to 2000 grit silicon carbide papers, 6 and $1 \mu \mathrm{m}$ diamond slurries, and then with $0.04 \mu \mathrm{m}$ aluminum oxide. The specimens were dehydrated in an ascending series of ethanol then critical-point dried with HMDS and mounted on aluminum stubs then gold-sputter coated. The SEM (LEO, Model

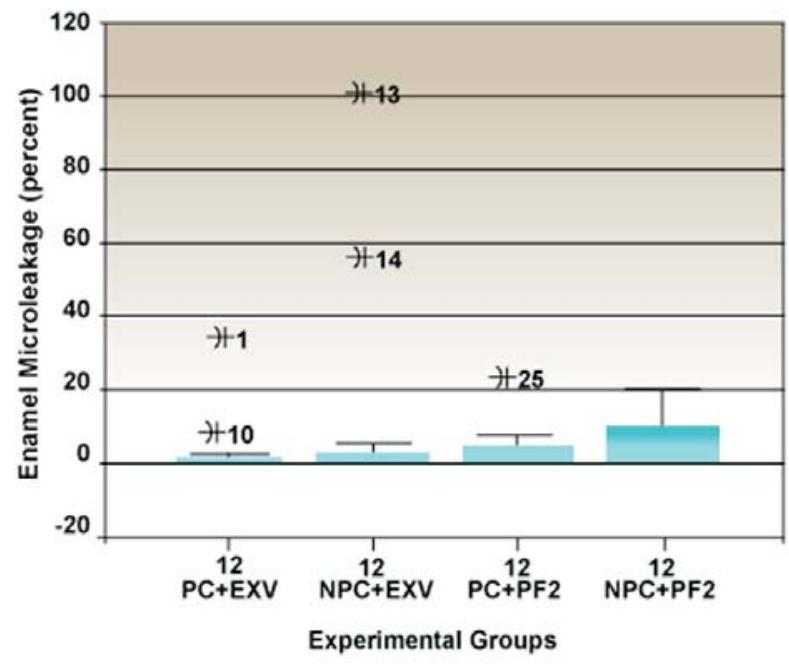

Figure 1. The enamel microleakage percentage in experimental groups.
VP-1450, Germany) was then used to assess marginal adaptation, hybrid layer, and cement layer thickness at enamel and dentinal margins at 1050x magnification.

\section{Results}

\section{Evaluation of Microleakage}

Figures 1 and 2 and Table 4 show microleakage of dentinal and enamel margins of specimens.

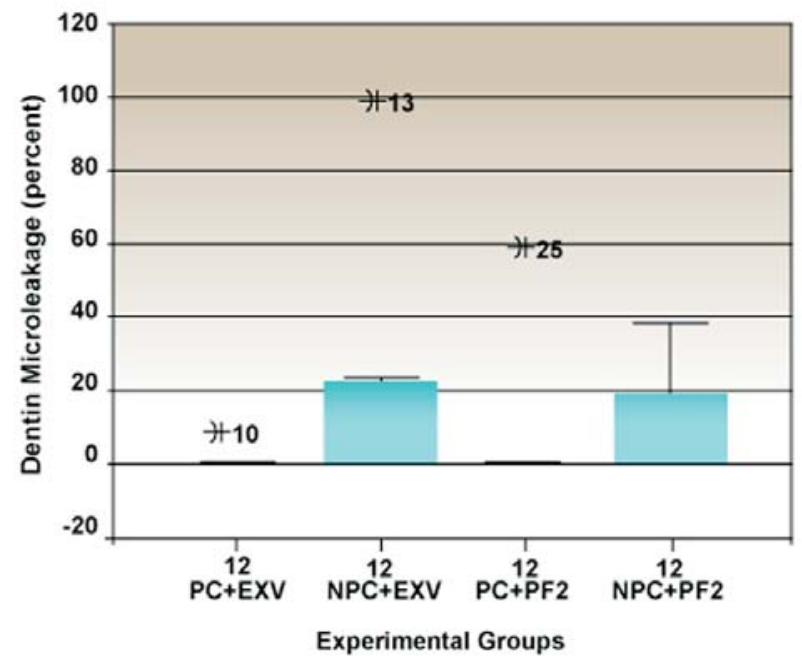

Figure 2. The dentin microleakage percentage in experimental groups.

Table 4. The microleakage mean ranks of enamel and dentinal margins in the experimental groups.

\begin{tabular}{|l|l|c|c|}
\hline \multicolumn{1}{|c|}{ Tooth Structure } & \multicolumn{1}{|c|}{ Group } & N & Mean Rank \\
\hline \multirow{5}{*}{ Enamel } & PC+EXV & 12 & 22.67 \\
\cline { 2 - 4 } & NPC+EXV & 12 & 23.75 \\
\cline { 2 - 4 } & PC+PF2 & 12 & 24.50 \\
\cline { 2 - 4 } & NPC+PF2 & 12 & 27.08 \\
\cline { 2 - 4 } & Total & 48 & \\
\hline \multirow{5}{*}{ Dentin } & PC+EXV & 12 & 18.50 \\
\cline { 2 - 5 } & NPC+EXV & 12 & 31.08 \\
\cline { 2 - 5 } & PC+PF2 & 12 & 19.50 \\
\cline { 2 - 5 } & NPC+PF2 & 12 & 28.92 \\
\cline { 2 - 5 } & Total & 48 & \\
\hline
\end{tabular}


Table 5. Descriptive statistics of mean, standard deviation, maximum, and minimum of dye penetration in enamel and dentinal margins.

\begin{tabular}{|l|l|c|c|c|c|c|}
\hline Tooth Structure & Group & $\mathrm{N}$ & Mean & Std. Deviation & Minimum & Maximum \\
\hline \multirow{5}{*}{ Enamel } & PC+EXV & 12 & 3.7050 & 10.075 & .00 & 35.00 \\
\cline { 2 - 7 } & NPC+EXV & 12 & 13.3775 & 31.618 & .00 & 100.0 \\
\cline { 2 - 7 } & PC+PF2 & 12 & 3.1508 & 6.420 & .00 & 21.74 \\
\cline { 2 - 7 } & NPC+PF2 & 12 & 4.5167 & 6.707 & .00 & 20.00 \\
\hline \multirow{5}{*}{ Dentin } & PC+EXV & 12 & .5950 & 2.0611 & .00 & 7.14 \\
\cline { 2 - 7 } & NPC+EXV & 12 & 17.376 & 27.842 & .00 & 100.00 \\
\cline { 2 - 7 } & PC+PF2 & 12 & 5.000 & 17.320 & .00 & 60.00 \\
\cline { 2 - 7 } & NPC+PF2 & 12 & 10.287 & 13.011 & .00 & 38.46 \\
\hline
\end{tabular}

The Kruskal-Wallis and Mann-Whitney tests revealed the method of curing had significantly affected microleakage in dentin margins $(P=0.03)$, but the type of material had no significant effect. The minimum and maximum mean rankings in dentinal margins were found in Group A and Group B in dentinal margins, respectively. Significant differences were detected for the values of microleakage in dentin margins $(P=0.01)$. The Mann-Whitney test showed the differences between Groups A and B ( $P=0.02)$.

Table 5 shows descriptive statistics of microleakage in enamel and dentinal margins of each group.

\section{SEM Evaluation}

Prior to sectioning of the specimens the veneered material seemed clear, smooth, and without any gaps when viewed macroscopically. However, when viewed microscopically, excess cement was observed in all specimens. The SEM analysis revealed the thickness of the resin cement layer to be more similar in Groups A and B compared to Groups C and D.

While the marginal adaptation in the enamel margins was suitable in all groups, the gaps between the enamel and the cement were less in all groups than the gaps found in dentin margins. This finding was consistent with the microleakage values achieved. More gaps appeared in the dentin margins of Group D, which was somewhat
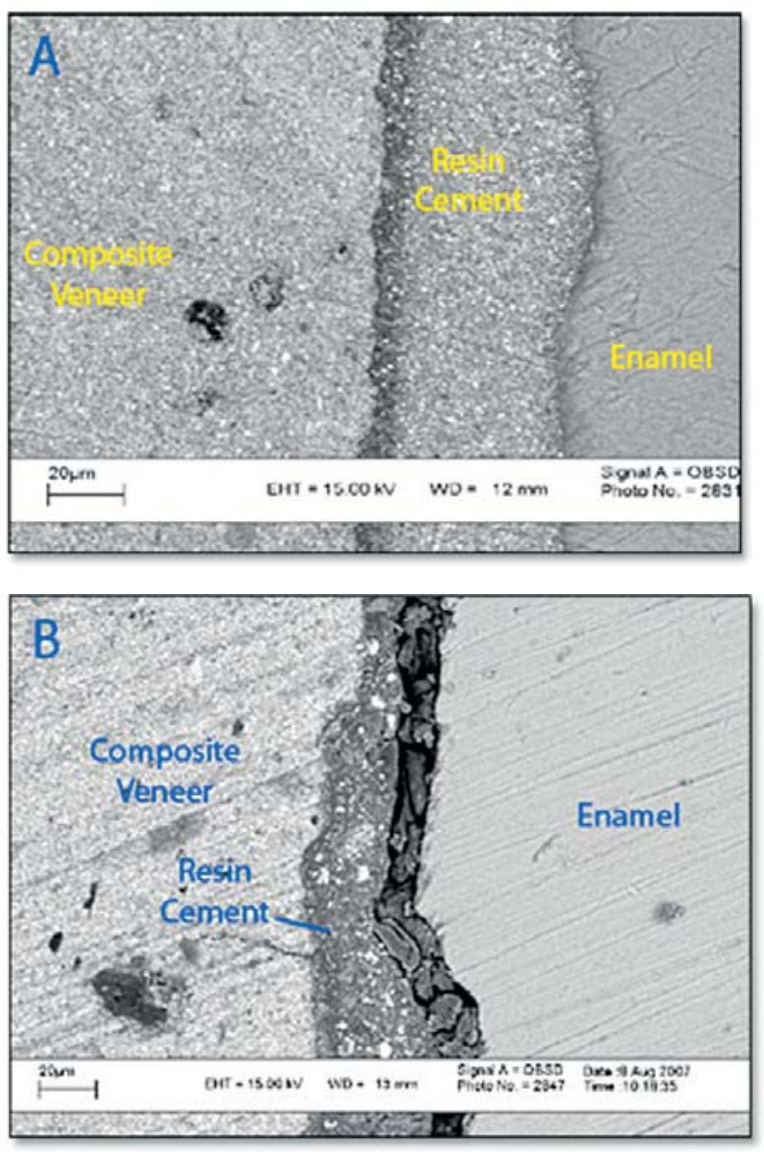

Figure 3. Interface area of composite veneer to enamel in groups. A. Photomicrograph of PC+EXV. B. Photomicrograph of PC+PF2. Magnification: 1050x. 

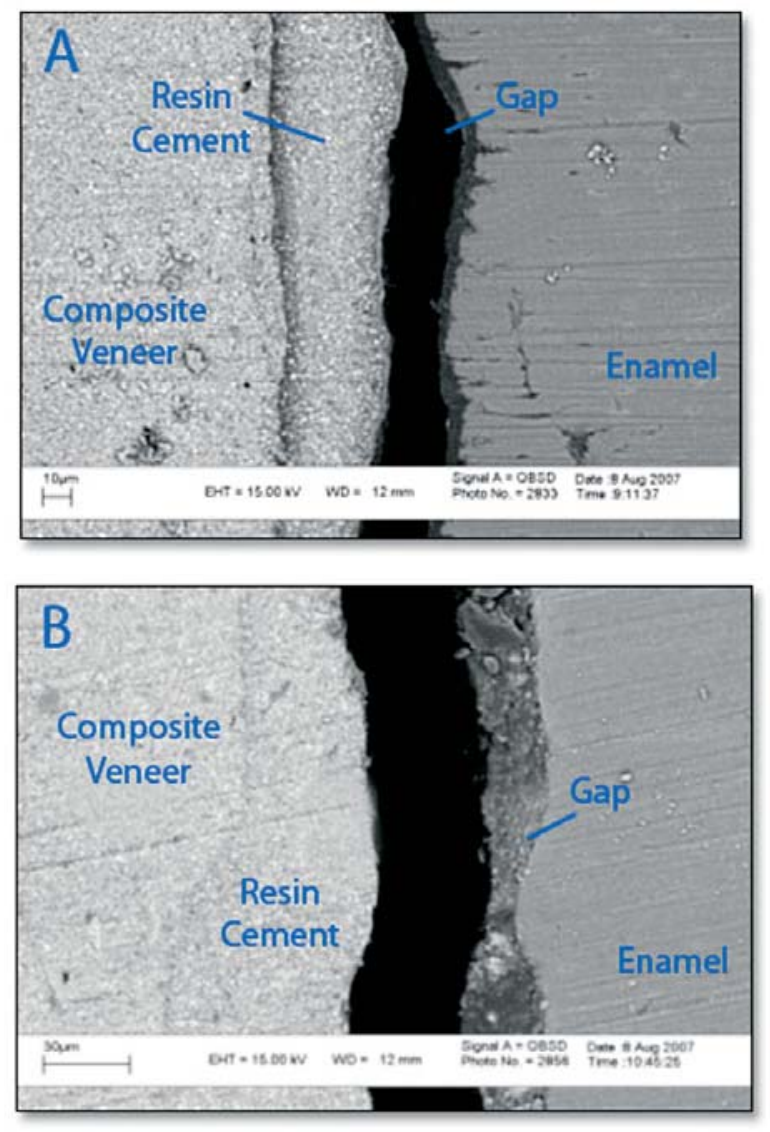

Figure 4. Interface area of composite veneer to enamel in groups. A. Photomicrograph of NPC+EXV (A) B. Photomicrograph of NPC+PF2. Magnification: 1050x.

similar to Group B, which confirmed the dye penetration and microleakage values according to the gap numbers and volumes. In both luting systems the gaps appeared in the adhesive/resin cement interface in the PC groups and in the tooth/adhesive interface or in the adhesive layer in the NPC groups (Figures 3 and 4).

\section{Discussion}

Microleakage and marginal adaptation of indirect composite veneers luted with two resin cements using different application procedures were evaluated in this study. Resin composite veneers were chosen for this research because they offer the advantage of being more user-friendly clinically and in the dental laboratory. ${ }^{13}$

Marginal leakage is one of the major drawbacks of tooth colored restorations so the dye penetration method was used in this study to assess microleakage while the marginal fit of cemented restorations can be estimated by either invasive or non-invasive techniques. A non-invasive technique leaves the tooth intact and can be a quantitative SEM analysis describing the entire margin area from replicas and microphotographs or from a microscopic assessment of the width of the luting cement at selected points along the margin. ${ }^{14,15}$ The quantitative SEM analysis provides information of the surface area but not of the overall fit of the restorations.

According to Hung et al. ${ }^{16}$ the invasive method based on multiplied sectioning can be more precise than the non-invasive method. A possible explanation might be the absolute marginal discrepancy appears better defined and easier to determine in a section in comparison to an intact surface. The present investigation confirmed this hypotheses: the clinical success of indirect composite veneers correlates with the properties of the resin cement luting agent and its method of application. Although Excite/VarioLink II is a totaletch resin cement system and Panavia F2.0 is a self-etch bonding system, both performed similarly in this study. The NPC method suggests by not pre-curing the adhesive prior to seating an indirect restoration, interference by the thickness of cured adhesive with complete seating is prevented. However, insufficient curing of the adhesive can lead to incomplete consistency of the hybrid layer and create the potential of marginal percolation and bacterial penetration in the dentin/adhesive interface as well as marginal discoloration, secondary decay, and post-operative sensitivity. ${ }^{17}$

Despite the film thickness of both luting systems used in this study, film thickness is usually thin enough not to interfere with the seating of indirect restorations, the thickness is not identical in all positions on the prepared tooth. As a result, it can be assumed a cured adhesive layer could interfere with the seating of indirect restorations. In the present study pre-curing the adhesive with both the Panavia F2.0 and Excite/VarioLink II systems significantly reduced microleakage despite manufacturer recommendations not to pre-cure their adhesives prior to cementation.

The favorable results achieved using the precuring method in this study were consistent with previous investigations. ${ }^{6,12,17}$ The absence of a 
visible adhesive layer when the adhesive is not pre-cured can be explained by the incorporation of the adhesive resin into the fluid resin cement.

In the present study pre-curing of the adhesive increased the luting space but reduced microleakage; the effect of pre-curing of the adhesive was not dependent on the type of material. The thickness of the adhesive layer was occasionally too thin in the NPC groups and microleakage was greater especially in dentin margins. Because dentin bonding is more sensitive than enamel bonding, pre-curing the adhesive in dentin margins is critical and will yield better results in terms of reduced microleakage than not pre-curing the adhesive. Compared to direct veneer restorations, the volumetric shrinkage of resin composite is less in indirect composite veneers due to the favorable $\mathrm{C}$-factor associated with veneer preparations. ${ }^{18}$

For the bond between the bonding layer and dentin to remain intact, stress associated with material shrinkage has to be relieved by an elastic response of surrounding materials. ${ }^{19}$ Although the beneficial effect of pre-curing the adhesive can be attributed to an increase in the degree of polymerization, the creation of an "elastic cavity" wall that absorbs some of the shrinkage stress of the luting resin cement might have contributed to the improvements observed which suggests the resin dentin hybrid layer can act as a stressabsorbing layer during functions. ${ }^{20}$

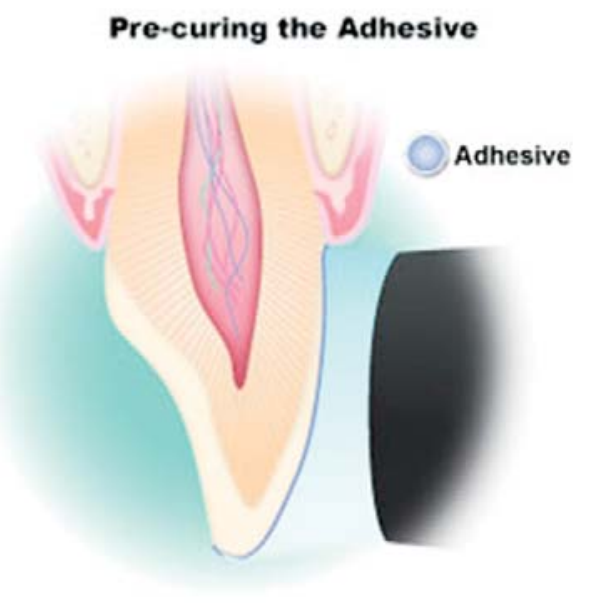

According to the results of this study, no significant differences were achieved between the two systems, and the microleakage appeared independent of material type, but the effect of curing method was significant. On the other hand, the quality of marginal adaptation is dependent on the combination of bonding system and luting resin cement rather than each material by itself. ${ }^{21}$ Despite the achievement of a thinner adhesive and hybrid layer using the Panavia F2.0 system, its effect on reducing microleakage and marginal defects was similar to the Excite/VarioLink II system during this investigation.

According to Stavridakis et al. ${ }^{22}$ the incidence of marginal gap is found to be independent of the width of the luting space ranging from 50 to $1000 \mu \mathrm{m}$. From a clinical viewpoint, the luting gap should be kept as small as possible in order to avoid pulling out any uncured material from the gap during removal of excess cement. ${ }^{23}$ Although curing the adhesive prior to cementation increases the luting space, this negative effect may be tolerable if a careful technique is used. Further investigations are necessary to determine the real influence of the pre-curing and adhesive thickness on the internal and marginal adaptation of indirect restorations and bond strength.

\section{Conclusion}

1. The effect of adhesive pre-curing on the microleakage and marginal adaptation was not related to material type.

2. Minimal microleakage was achieved in precured specimens with both cements studied.

3. Microleakage in dentin margins as opposed to enamel margins was significantly related to curing methods.

4. Adhesive pre-curing causes a greater filmthickness of resin cement.

5. The border between the adhesive and cement were not detectible by SEM analysis in the specimens with no pre-curing of the adhesive.

\section{Clinical Significance}

Different curing methods (with pre-curing/without pre-curing) regardless of total-etch or self-etch adhesive systems influenced microleakage and the marginal adaptation, especially dentin margins of indirect composite veneers. 


\section{References}

1. Rosenstiel SF, Land MF, Crispin BJ. Dental luting agents: a review of the current literature. J Prosthet Dent 1998; 80:280-301.

2. Peumans M, Van Meerbeek B, Yoshida Y, Lambrechts P, Vanherle G. Porcelain veneers bonded to tooth structure: an ultramorphological FE-SEM examination of the adhesive interface. Dent Mater 1999; 15:105-19.

3. Peumans M, Van Meerbeek B, Lambrechts P, Vanherle G. Porcelain veneers: a review of the literature. J Dent 2000; 28:163-77.

4. Dhawan $\mathrm{P}$, Prakash $\mathrm{H}$, Shah N. Clinical and scanning electron microscopic assessments of porcelain and ceromer resin veneers. Indian J Dent Res 2003; 14:264-78.

5. Soares CJ, Soares PV, Pereira JC, Fonseca RB. Surface treatment protocols in the cementation process of ceramic and laboratory-processed composite restorations: a literature review. J Esthet Restor Dent 2005; 17:224-35.

6. Haller B. Recent developments in dentin bonding. Am J Dent 2000; 13:44-50.

7. Ferrari M, Patroni S, Balleri P. Measurement of enamel thickness in relation to reduction for etched laminate veneers. Int J Periodontics Restorative Dent 1992; 12:407-13.

8. Gladys S, Van Meerbeek B, Lambrechts P, Vanherle G. Microleakage of adhesive restorative materials. Am J Dent 2001; 14:170-76.

9. Alani AH, Toh CG. Detection of microleakage around dental restorations: a review. Oper Dent 1997; 22:173-85.

10. Cox CF, Felton D, Bergenholtz G. Histopathological response of infected cavities treated with Gluma and Scotchbond dentin bonding agents. Am J Dent 1998; 1:189-94.

11. Hekimoglu C, Anil N, Yalcin E. A microleakage study of ceramic laminate veneers by autoradiography: effect of incisal edge preparation. J Oral Rehabil 2004; 31:265-70.

12. Ibarra G, Johnson GH, Geurtsen W, Vargas M. Microleakage of porcelain veneer restorations bonded to enamel and dentin with a new self-adhesive resin-based dental cement. Dent Mater 2007; 23:218-25.

13. Torstensen B, Brännström M. Composite resin contraction gaps measured with a fluorescent resin technique. Dent Mater 1988; 4:238-45.

14. Ferrari M, Dagostin A, Fabianelli A. Marginal integrity of ceramic inlays luted with a self-curing resin system. Dent Mater 2003; 19:270-6.

15. Inokoshi S, Van Meerbeck B, Willems G, Lambrechts P, Braem M, Vanherle G. Marginal accuracy of CAD/CAM inlays made with the original and the updated software. J Dent 1992; 20:171-7.

16. Hung SH, Hung KS, Eick JD, Chappel RP. Marginal fit of porcelain-fused-to-metal and two types of ceramic crown. J Prosthet Dent 1990; 63:26-31.

17. Chen RS, Liuiw CC, Tseg WY, Hong CY, Hsieh CC, Jeng JH. The effect of curing light intensity on the cytotoxicity of a dentin-bonding agent. Oper Dent 2001; 26:505-10.

18. Feilzer AJ, de Gee AJ, Davidson CL. Increased wall-to-wall curing contraction in thin bonded resin layers. J Dent Res 1989; 68:48-50.

19. Kemp-Scholte CM, Davidson CL. Complete marginal seal of Class V resin composite restorations effected by increased flexibility. J Dent Res 1990; 69:1240-3.

20. Uno S, Finger WJ. Function of the hybrid zone as a stress-absorbing layer in resin-dentin bonding. Quintessence Int 1995; 26:733-8.

21. Alster D, Feilzer AJ, de Gee AJ, Davidson CL. Polymerization contraction stress in thin resin composite layers as a function of layer thickness. Dent Mater 1997; 13:146-50.

22. Stavridakis MM, Krejci I, Magne P. Immediate dentin sealing of onlay preparations: Thickness of pre-cured dentin bonding agent and effect of surface cleaning. Oper Dent 2005; 30:747-57.

23. Haller B, Habner K, Moll K. Marginal adaptation of dentin bonded ceramic inlays: effects of bonding systems and luting resin composites. Oper Dent 2003; 28:574-58. 


\section{About the Authors}

\section{Fathemeh Maleknejad, DDS, MS}

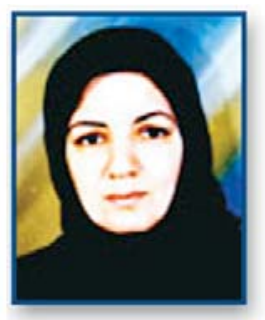

Dr. Maleknejad is an Associate Professor in the Department of Operative Dentistry, School of Dentistry Dental Research Center at Mashhad University of Medical Sciences in Mashhad, Iran. Her research interests include tooth bleaching, microleakage, and tooth colored restorative materials. Dr. Maleknejad is a member of the Iranian Academy of Cosmetic Restorative Dentistry.

e-mail: maleknejadf@mums.ac.ir

Horieh Moosavi, DDS, MS

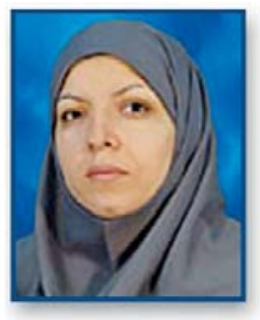

Dr. Moosavi is an Assistant Professor in the Department of Operative Dentistry, School of Dentistry Dental Research Center at Mashhad University of Medical Sciences in Mashhad, Iran. Her research interests include microleakage, adhesive systems, tooth colored restorative materials, and biomaterials. Dr. Moosavi is a member of the Iranian Academy of Cosmetic Restorative Dentistry and the IADR.

e-mail: moosavih@mums.ac.ir or dentist_57@yahoo.com

Resa Shahriari, DDS

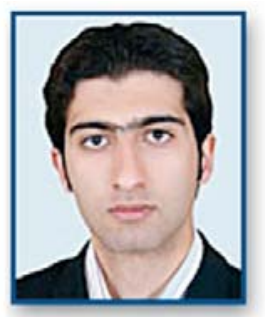

Dr. Shahriari is a general dentist in the Department of Operative Dentistry of the School Dentistry Dental Research Center at the Mashhad University of Medical Sciences in Mashhad, Iran. His research interests include cosmetic dentistry, dental materials, microleakage, and cosmetic dentistry.

e-mail: reza.shahriari@gmail.com

Nasrin Sarabi, DDS, MS

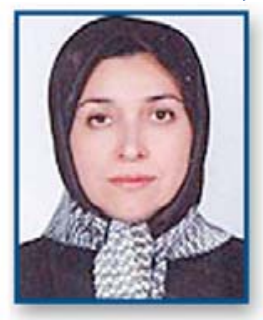

Dr. Sarabi is an Assistant Professor in the Department of Operative Dentistry of the School Dentistry Dental Research Center at the Mashhad University of Medical Sciences in Mashhad, Iran. Her research interests include tooth bleaching, tooth colored restorative materials, and indirect restorations. She is a member of the Iranian Academy of Cosmetic Restorative Dentistry.

e-mail: sarabin@mums.ac.ir 


\section{Taybeh Shayankhah, DDS}

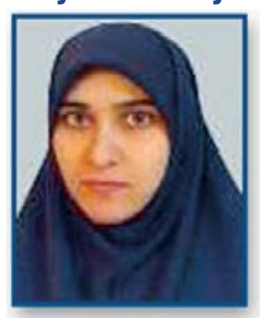

Dr. Shayankhah is a general dentist in the Department of Operative Dentistry of the School Dentistry Dental Research Center at the Mashhad University of Medical Sciences in Mashhad, Iran. Her research interests include cosmetic dentistry, dental materials, microleakage, cosmetic dentistry, and indirect restorations.

\section{Acknowledgement}

This study was supported by a grant from the Dental Research Center and Research Council of Mashhad University of Medical Sciences in Mashhad, Iran. 